\title{
Transformative Social Protection: Reflections on South Asian Policy Experiences
}

\author{
Gabriele Koehler*
}

\begin{abstract}
This article argues that social transfers as such, are a 'good thing'. They can alleviate the immediate economic impact of poverty and vulnerability. It cautions, however, that such transfers may be a 'bad thing', since they can divert attention from the real obstacles to equitable, inclusive development and social justice, and postpone actions for structural change. The article examines social transfers in the form of income supplements, employment guarantees, and transfers for affirmative action in Bangladesh, India, Nepal and Pakistan. It argues that additional factors are needed to render such social protection policy instruments genuinely transformative. These would include transparency of information and freedom of the press, among others. They would also include policies to address land reform, an industrial strategy to create decent work, progressive fiscal policy, policies for social inclusion and policies at the international level.
\end{abstract}

\section{Introduction}

Across the global South, many social protection policies and measures have been introduced, scaled-up or consolidated in recent years (Devereux and Sabates-Wheeler 2004), prompting some authors to speak of a 'quiet revolution' (Barrientos and Hulme 2009: 452) or even a 'startling' process (Devereux and SabatesWheeler 2007: 1). In recent history, increased attention to social protection is frequently associated with the global economic crisis of 1998, when several countries in East and South-

East Asia began introducing schemes to alleviate the economic situations of the 'new poor' (Cook and Kwon 2007), or the experience in Latin America, where neoliberal structural adjustment programmes intensified poverty during the 1980 s, prompting governments to introduce large-scale social transfer schemes.

Most recently, social protection measures have also become associated with the momentum and pressure on governments around the Millennium Development Goal (MDG) agenda. The performance on various MDG targets is highly uneven. Some countries are on track at the aggregate level, which is positive, although one is aware that the targets were not very ambitious, so that the progress achieved is modest. Moreover, when looking beyond the aggregate level, disadvantaged groups are not benefiting from the MDG progress. The UN General Assembly (2010) MDG meeting therefore added concepts of social exclusion and for the first time spelt out policy recommendations for social protection in its outcome document (UN General Assembly 2010; UN DESA 2009; Kabeer 2010; Koehler and Voipio 2010).

This interest in social protection policies, and the introduction or expansion of social transfers as one prominent instrument within social protection, are a 'good' thing. This is because social transfers can alleviate the immediate economic impact of poverty and vulnerability, by providing a supplementary source of income, or offering a transfer in kind, and help prevent pernicious coping strategies such as sale of assets, reducing meals or foregoing health or education services. They can help create a sense of socioeconomic security. Provided tax-funded social assistance transfer amounts are sufficiently generous and broad in coverage, they can even constitute first steps towards income redistribution. In certain cases, social transfers can also contribute to improving chances for 
social inclusion or political voice. Employment guarantee schemes can have a more far-reaching impact if they are introduced as a right to decent work, at minimum wage conditions and with associated workers' rights, so that they have spill-over effects on the larger economy. Social transfers can - in ideal circumstances constitute a step towards social transformation and a step on the path towards social justice.

However, social transfers may at the same time be a 'bad' thing: they may well be a palliative that serves to divert attention from the real obstacles to equitable, inclusive development and social justice, and postpone actions which would initiate the necessary structural change. This is because social transfers do not per se challenge basic economic and political power relations, neither at the local nor at the economy-wide level.

Furthermore, they do not fundamentally address asset inequality and the absence of decently remunerated, dignified, long-term productive employment that are the core causes of persistent vulnerabilities, poverty and socioeconomic insecurity. Social transfers can alleviate, but not eliminate, the processes and constellations creating poverty, since benefit levels are in most countries modest and do not enable a household to acquire, or even merely lease, productive assets. Public works schemes do not create decent, sustained, long-term employment in a dignified workplace. A development policy question is therefore whether and how social protection policy and its instruments can be conceptualised in a more transformative fashion that would tackle, and ultimately overcome, the root causes of poverty and vulnerability.

This article reviews social protection experiences in Bangladesh, India, Nepal and Pakistan. They are primarily in the form of social transfers, but are complemented by measures that introduce minimum labour standards, affirmative action and the right to information. This article examines to what extent these social protection schemes display transformative potential. The policy intent and design are of primary interest here, since poor outcomes may be due to any of a range of factors, from poor policy formulation, to inefficient implementation, sabotage, lack of funds or of a monitoring process, or political economy dynamics and hijacking by other interest groups, and because evaluations of impact and implementation effectiveness are sketchy at best.

\section{Social protection policy in four South Asian countries}

In South Asia, social protection policy can be understood as an element in the broader welfare regime approaches introduced in these countries at independence (see Ehmke, this IDS Bulletin). Despite performing poorly on most social indicators - notably on food and nutrition security - the region is increasingly recognised for many innovations at the policy level which are seen to have potentially transformative features. Some have even argued that these innovations represent a new, 'southern' cash transfer paradigm (Hanlon et al. 2010), originating as they do in developing countries, and displaying four common principles:

- They are rights-based, with transfers funded by the government, reinstating a role for the state.

- They are longer-term transfers, with recipients confident of receiving them.

- They cover a significant proportion of the population.

- They are part of a development strategy (Hanlon et al. 2010: 20).

Political change in several countries - new governments in India (2005), Pakistan (2008) and Bangladesh (2009) and the end of civil conflict in Nepal (2006) - created political pressure, political will, as well as policy space for such social policy innovations.

In India, the leftist parties in the 2005 coalition government made a strong case for addressing unemployment, poverty and income inequality, pushed by the popular protest movement which had contributed to their electoral success: the Mahatma Gandhi National Rural Employment Guarantee Act (MGNREGA), in particular, was a response to popular mobilisations protesting the conditions facing many rural poor as a result of the economic liberalisation policies introduced since the early 1990s (see Drèze, in Stewart 2010).

In Nepal, the post-conflict interim government of 2007 felt that 'poverty and social exclusion' as the root causes of the conflict needed to be tackled and hence introduced a series of improvements in existing social policy measures and also added new measures. This was driven by a spirit of 'the new Nepal' at the end of the conflict, the new elected government and the 
redefinition of Nepal as a secular republic, replacing a Hindu monarchy.

In Pakistan, the election of a civilian government in 2008 was the trigger for policy innovations. It was a government that was 'critical of economic management under the previous government, and particularly of perceived increases in income inequality. There was strong political will... to combine stabilisation with measures for protecting consumption levels of the poor and the vulnerable' (Gazdar 2011: 7). This political pressure for pro-poor measures was increased by the competition between the federal government and the government of Punjab.

In Bangladesh, a new government was elected in 2008, which in its election manifesto referred to the global economic and financial crisis and proffered a welfare state 'where every citizen is assured of social justice, environmental protection, human rights and equal opportunities; and where the rule of law and good governance flourish' (Awami League 2008). The main strategy of poverty reduction would centre on agriculture and the rural economy, extending social safety nets for the ultra-poor, and by 2013 reducing the number of the ultrapoor from 65 million to 45 million. This was to be achieved by a range of social protection policies (Awami League 2008).

This suggests that a combination of political power transitions, political competition among rival factions, and the impact of the financial crisis are some of the political contexts leading to the scale-up of the existing, largely fragmented schemes for social assistance and poverty alleviation. In some instances, the social protection initiatives have become part of a deeper reform, with complementary rights-based legislation coming on stream. In particular, India's suite of rights-based social projection policies - the right to school meals and to food; the right to education; the right to social protection for the informal sector; the employment guarantee and the right to information (Koehler 2010), has prompted Barrientos and Hulme (2009: 445) to ascribe a 'regional leadership role' to this country. Indeed, several of India's social protection policies have seen policy diffusion - the employment guarantee act has been replicated in Bangladesh, Nepal and Pakistan, and a right to information act has recently been introduced in Bangladesh and Nepal (Government of Nepal 2009; Government of Bangladesh 2009).

\section{Selected examples of South Asian social protection policies ${ }^{1}$}

Three types of social protection policies are selected, since they are presented as rights-based and include affirmative action. They can thus be understood as oriented to social justice, even if this is not explicitly spelt out. They are:

- social transfers;

- employment guarantees;

affirmative action.

\subsection{Social transfers for supplementary income}

One of the oldest social protection measures in South Asia is Nepal's social pension scheme, introduced in 1995. It is universal by category at inception, all Nepali citizens over the age of 75 were eligible for a small monthly benefit, disbursed by district development councils on a quarterly basis. Driven by the momentum of post-conflict Nepal, the coalition government in its first fiscal budget in 2008/09 brought the age threshold down to 70 years, and doubled the benefit amount to 500 rupees (approximately US\$7) per month (Koehler et al. 2009). The transformation potential derives from the fact that it is entirely citizenship-based, creating a sense of entitlement by virtue of having contributed to the economy and society in the course of one's life. Moreover, despite the low level of the benefit, in low-income rural areas, the amount received gives some - albeit small financial autonomy to the elder family member.

In Pakistan, the Benazir Income Support Programme (BISP), introduced in 2008, is a scheme to promote 'equal opportunities and social justice', and 'poverty alleviation and women empowerment among the underprivileged section of Pakistani society'. It was initially a grant for social assistance devolved to each parliamentarian to disburse grants in his or her constituency using subjective needs assessments. In 2009, this nontransparent modality was replaced by eligibility screening in the form of a poverty scorecard system - proxy means testing. Cash transfers of 100 rupees (US\$12) per month are reportedly made to roughly 430,000 beneficiaries. Similarly, BISP has added victims of the 2010 flood disaster, which would raise the number of registered BISP 
families to 7 million, suggesting as many as 35 million individual recipients. It has a target of a 20 per cent decrease in poverty by 2014 . Complementary measures, in the direction of asset building, include the Waseela-e-Haq programme, promoting small entrepreneurship, and the Waseela-e-Rozgar, a free skills development and vocational training plan. There is also life insurance for the breadwinner of beneficiary families.

There are several potentially transformative elements in BISP. The modality of disbursing to the family unit means that in multi-generational households where more than one nuclear family lives together, each family carries its own entitlement. Women, as entitlement holders, require a citizenship card as well as a bank account in their own name. This gives women in low-income households an unprecedented degree of visibility and conceivably some status in the family (Raja 2010). 'The decision to identify women as primary beneficiaries represented a break from past practice and institutional habit of constructing the relationship between the state and individuals through the male heads of family' (Gazdar 2011: 8).

\subsection{Employment guarantees}

In current social protection literature, the 'revolution' in the South is frequently associated with India's Mahatma Gandhi National Rural Employment Guarantee Scheme (MGNREGS), adopted in 2005 and introduced in 2006. The rights orientation lies in the fact that employment is guaranteed and notionally must be made available on request. Critics stress the tough working conditions, the fact that the social transfer is conditional on hard work with few amenities, whereas supporters emphasise the right to work, the adherence to state-level minimum wage laws and the process whereby, if a worksite is not created, the state government must provide an unemployment allowance at a rate agreed at the state level (Government of India 2008: 37).

The MGNREGS model was replicated in Bangladesh as the Employment Generation Programme for Hard-Core Poor, introduced initially as the Employment Generation Programme in 2008/09 (Government of Bangladesh, no year). It applies to rural areas of the country, with priority in 81 highly poverty- prone sub-districts (upazillas). The government allocated 200,000,000 Taka in 2008/09 and $117,600,000$ Taka in 2009/10. The objectives are to create employment for extremely poor unemployed people in rural areas; increase the purchasing power of the extreme poor people affected by price hikes, notably food price inflation; and develop and maintain small-scale rural infrastructure and communication systems. The scheme was introduced because of seasonal poverty which prevails for roughly three months per year, and is meant to benefit 2 million 'hard core poor families' or roughly 10 million beneficiaries in a total of 64 districts, one person from each family, male or female, who are not receiving benefits from other ongoing social safety nets. The government recorded a total of 2 million labourers with almost 90 million workdays created, with employment roughly 80 per cent men and 20 per cent women. The wage rate is 100 Taka per day (approximately US\$1.35). There is an unemployment allowance, modelled on the Indian example - if an applicant fails to receive a job within 15 days of registration, she or he will receive a social transfer (Government of Bangladesh, no year). This again is an interesting combination of an employment scheme linked to social protection.

Similarly in Pakistan, an employment generation scheme for rural unskilled workers is to guarantee employment, again for 100 days a year. The scheme is devoted to small local level works with a guaranteed daily wage equal to the minimum wage. A pilot scheme was announced in 2010 for the 12 least developed districts and districts that have suffered from the security situation. Five billion rupees are being allocated for this programme and 200,000 households are to be covered by the scheme in its first year (Minister for Finance, Government of Pakistan 2010).

In Nepal, the Karnali Employment Programme (KEP) is designed to arrange for 100 days of employment for persons out of employment in Karnali, the poorest region of Nepal, with a population of approximately 350,000 . The government budget allocation is 250 million rupees. It was piloted in 2006/07, and adopted as a policy in 2010 . It was reported that over 60,000 of the 64,000 households in these districts of the Karnali Zone had found employment equivalent to 15 days in the programme's first year (National News Agency 2010). Contrary to the 
other three South Asian countries, however, the government of Nepal has not cast the KEP as a guarantee, and coverage is low. Nevertheless, it offers a notion of an entitlement to a minimum income and to a job, a novelty in Nepal.

\subsection{Affirmative action}

Social exclusion based on gender, caste, ethnicity, language, religious affiliation, age and other vectors of identity, is pervasive across South Asia and one of the main obstacles to social justice. Many schemes have been designed to address and overcome exclusion, especially with respect to gender and caste.

The Bangladesh government introduced a secondary school stipend as early as 1994 for all girl children, regardless of the economic situation of the family. It is conditional on school attendance, school performance and remaining single. Its purpose was to address the gender gap in education, and in that respect, the stipend has been successful - girls' secondary school enrolment stands at 42 per cent, compared with 22 per cent in 1989; in fact, the gender gap has been reversed (Asadullah and Chaudhury 2009: 1372), and the scheme may now be extended to all secondary school children to encourage more boys to continue schooling.

In Nepal, education incentives have been in place for many years, and were scaled-up in connection with the Education for All Programme adopted in 2004. School stipends are available for girls and for children from disadvantaged castes, implemented by the Ministry of Education and Sport, and each school has a School Management Committee which selects the eligible children, and distributes and monitors the scheme (Koehler et al. 2009). The intent is clear: to overcome the family and community-level entrenched resistance to the education of girl children and children from the Dalit caste.

Several states in India have developed girl child grants, designed to halt the significant female foeticide and infanticide. In one of these programmes, introduced in 2006 in Madhya Pradesh, girl children registered at birth are to receive an accumulated fund of approximately 180,000 rupees (US\$2,700) from the state government at the time of marriage. The objective of the scheme is to improve health and educational facilities for girl children 'by providing a bright future' and to stop female foeticide (Government of India 2007). A similar scheme in Tamil Nadu deposits 22,200 rupees (approximately US $\$ 500$ ) for each girl child at birth, which she is to receive at age 20, while the interest is available to her family for educational expenses (Government of India 2007; Srinivasan and Bedi 2009).

It is debatable whether monetary incentives can address sociopolitical exclusion, and to what degree this could be described as a transformative approach. What is important, nevertheless, for a transformative agenda, is that social exclusion is hereby systematically acknowledged as a key challenge and as a violation of rights.

\section{Outlook - transformative social protection policies}

These social protection policies are a big step forward because they acknowledge the gravity of poverty, unemployment and social exclusion. They are a policy effort towards addressing these situations, and they are cast as rights which citizens can claim. But - are they transformative?

That depends on how 'transformation' is understood. One influential definition of transformation stresses that 'social protection interventions should extend well beyond social transfers... to include redistribution of assets that will reduce dependence on handouts and enable at least some poor people to achieve sustainable livelihoods' (Sabates-Wheeler and Devereux 2007: 24). This would encompass strategies to integrate individuals equally into society and enable excluded and marginalised groups to claim their rights, and measures to transform public attitudes and change regulatory frameworks. Another criterion is sensitivity to exclusion. Thus, Kabeer (2010) recommends policies for social inclusion as integral to social protection, and Koehler (2009) proposes dedicated social inclusion policies as well as inclusiveness in macroeconomic and sectoral policies.

Building on these ideas, and reflecting the South Asian conceptual policy developments, a tentative 'layout' of criteria for 'transformation' might include:

- universal coverage or clearly delineated categorical entitlements, but incorporating 
special measures to ensure that women, children and socially excluded groups can claim their rights;

- longevity and predictability of the scheme, anchored in government fiscal budgets;

- policies triggered by citizens and programme design that build in the preferences and priorities of participants; gender empowerment and voices of the excluded and those living in poverty need to be central to the conceptualisation and realisation of policy;

- a rights-based approach that is justiciable, with transparency and uniformity in eligibility criteria, entitlements, and programme delivery and an established process through which citizens can claim their rights;

- approaches that create productive assets or continuous income streams for the individual, household and community concerned and which thereby constitute a process of graduation, moving social protection from a dependency mode into a modality enabling a transition into productive livelihoods, decent work and security of productive assets.

In terms of the broader sociopolitical context, the degree of transformation that might result from social protection measures depends on a set of factors reaching beyond socioeconomic security. The first is the extent to which rights can be claimed. This is driven by legislation proper as well as by transparency and accessibility of information, freedom of the press, an independent and vibrant civil society and genuine citizens' voice in party politics, parliaments and other political institutions. These require domestic legislation as well as access to inclusive and effective legal aid, so that citizens know and can claim their rights.

Moreover, the households and communities, which subsist on ad hoc daily wage labour and casual jobs, are highly dependent on village landowners, elites and powerbrokers and are often subjected to processes of silent or open violence. They need to be assured that claiming their rights, or for example participating in social protection schemes such as public works, will not jeopardise their social relations and local employment prospects in the future.

Thus, affirmative action and the right to information acts in India, Bangladesh and Nepal, combined with democratic institutions such as the media, trade unions and civil society movements, are crucial complements to transformative social protection. The first four of the criteria for transformation above refer to this.

A broader notion of transformation would, however, need to encompass macro-level and sectoral economic policies. Here too, there are major gaps. With respect to the skewed distribution of assets, the small size of the benefits (and the minimalism of microcredit schemes - not discussed here due to space restrictions) cannot alter income and wealth distribution patterns. More fundamentally, policies to address land reform and a recalibrating of power relations in the rural economy are absent. Since dependence on rural landowners remains pivotal for survival of lowincome families and those living in absolute poverty, affirmative action in the political sphere, such as quotas for representation, will have limited impact on structural and redistributive change in economic relations.

An additional set of policies would therefore be necessary to render social protection policies 'transformative'. In terms of domestic policies, these include an industrial strategy to create decent work, housing policy, land reform, progressive fiscal policy and policies for social inclusion. At the international level, policies and actions - ensuring equitable international trade, investment and private finance as well as official development assistance (ODA), are also indispensable.

In light of these policy gaps, the 'quiet revolution' in social protection policies needs some qualification. The policies introduced in South Asia are necessary, useful and welcome: they provide much needed alleviation to dire situations, they can serve as a vital support towards improving socioeconomic security and addressing social exclusion, and they have been establishing themselves as key poverty-directed strategies. However, these social protection policies and measures do not per se change the situation of individuals, households and communities who are poor and vulnerable. But this is not what they are designed to do - so they cannot be criticised for this shortcoming. To be genuinely transformative, social protection needs to be embedded in a much broader policy architecture. First, it needs to look at domestic and regional policies towards generating 
sustained decent work and fundamentally revamping the rural economy and the informal sector. Second, it needs to look into globally reorganising the inequitable paradigms and logics of international trade, finance and investment.

\section{Notes}

* Gratefully acknowledging Stephen Devereux, Ellen Ehmke, J. Allister McGregor, Isabel Ortiz, Rachel Sabates-Wheeler and participants at the

\section{References}

Asadullah, M.N. and Chaudhury, N. (2009) 'Reverse Gender Gap. Female Stipends in Bangladesh', Journal of Development Studies 45.8: 1360-80

Awami League (2008) Election Manifesto of Bangladesh Awami League 2008: A Charter for Change, www.albd.org/autoalbd/index.php? option $=$ com_content $\&$ task $=$ view $\&$ id $=367 \&$ Itemid (accessed 2 August 2011)

Barrientos, A. and Hulme, D. (2009) 'Social Protection for the Poor and the Poorest in Developing Countries: Reflections on a Quiet Revolution', Oxford Development Studies 37.4: 439-56

BISP (Benazir Income Support Programme), Government of Pakistan, www.bisp.gov.pk (accessed 17 February 2011)

Cook, S. and Kwon, H. (2007) 'Social Protection in East Asia', Global Social Policy 7.2: 223-9

Devereux, S. and Sabates-Wheeler, R. (2007) 'Debating Social Protection', IDS Bulletin 38.3: $1-7$

Devereux, S. and Sabates-Wheeler, R. (2004) Transformative Social Protection, IDS Working Paper 232, Brighton: IDS

Gazdar, H. (2011) Social Protection in Pakistan: In the Midst of a Paradigm Shift?, Centre for Social Protection Research Report 13, Brighton: IDS

Government of Bangladesh, Ministry of Food and Disaster Management (no year) Brief on 100 Day Employment Generation Program, www.mofdm.gov.bd/100\%20day\%20egp.pdf (accessed 23 February 2011)

Government of Bangladesh (2009) Right to Information Act, www.ti-bangladesh.org/ banner_right/RTI-pap-210609-2.pdf (accessed 17 February 2011)

Government of India (2008) The National Rural Employment Guarantee Act (2005): Operational Guidelines, 3rd edn, New Delhi: Ministry of Rural Development, http://nrega.nic.in/Nrega _guidelinesEng.pdf (accessed 23 June 2011)
Otherwise, one may be caught up supporting a false revolution - far better than reactive safety nets - but certainly not genuinely transformative for inclusive social justice.

CSP conference for insightful comments on earlier versions of this article.

1 This section builds on and updates Koehler et al. (2009).

Government of India (2007) Ladali Lakshmi Yojna: Madhya Pradesh, http://india.gov.in/citizen/ health/viewscheme.php?schemeid $=1241$ (accessed 15 February 2011)

Government of Nepal (2009) Right to Information Act, http://right2info.org/resources/publications/ nepal-rti (accessed 17 February 2011)

Government of Pakistan, Minister for Finance Dr Abdul Hafeez Sheikh (2010) New Employment Generation Scheme Announced, 5 June, www.onepakistan.com/news/local/islamabad/ 47438-new-employment-generation-schemeannounced.html (accessed 31 July 2011)

Hanlon, J.; Hulme, D. and Barrientos, A. (2010) Just Give Money to the Poor: The Development Revolution from the Global South, New York: Kumarian

Kabeer, N. (2010) Can the MDGs Provide a Pathway to Social Justice? The Challenge of Intersecting Inequalities, www.ids.ac.uk/index.cfm?objectid= D7AF033E-A15A-2AEB-6946038681E30AF9 (accessed 31 July 2011)

Koehler, G. (2010) Südasien: Ansprüche und Elemente von Wohlfahrtsstaatlichkeit, Working Paper, University of Bielefeld Institute of World Society, www.uni-bielefeld.de/(de)/soz/ iw/publikationen/workingpapers.html (accessed 31 July 2011)

Koehler, G. (2009) 'Policies Toward Social Inclusion: A South Asian Perspective', Global Social Policy 9.1: 24-9

Koehler, G. and Voipio, T. (2010) 2010 - A Year of Innovations in the Global Poverty Reduction Agenda, www.networkideas.org/alt/jan2011/Reduction_ Agenda.pdf (accessed 31 July 2011)

Koehler, G.; Cali, M. and Stirbu, M. (2009) Social Protection in South Asia: A Review, UNICEF ROSA, www.unicef.org/rosa/ROSA_Evaluation Journal.pdf (accessed 31 July 201 1 )

National News Agency (2010) Karnali Employment Scheme 2010, www.rssnews.com.np/index.php? main $=19 \&$ start $=522 \&$ count $=1453($ accessed 9 July 2011) 
Raja, Farzana (2010) BISP Offers Rs.1,000 per Month Cash Assistance to its Beneficiaries, 13 May, www.thefreelibrary.com/Benazir + Income+ Support + Program + making + women + selfsufficient $\% 3 a+$ Farzana...-a0226461323 (accessed 13 September 2011)

Sabates-Wheeler, R. and Devereux, S. (2007) 'Social Protection for Transformation', IDS Bulletin 38.3: 23-7

Srinivasan, S. and Bedi, A.S. (2009) 'Girl Child Protection Scheme in Tamil Nadu: An Appraisal', Economic and Political Weekly 48: xliv Stewart, F. (2010) 'Power and Progress: Swing of the Pendulum', Journal of Human Development and Capabilities 11.3: 371-95
UN DESA (2009) Rethinking Poverty: Report on the World Social Situation, New York: United Nations, www.un.org/esa/socdev/rwss/docs/ 2010/fullreport.pdf (accessed 31 July 2011)

UN General Assembly (2010) Keeping the Promise: United to Achieve the Millennium Development Goals: Resolution Adopted by the General Assembly, United Nations A/RES/65/1, www.un.org/en/ $\mathrm{mdg} /$ summit2010/pdf/outcome_documentN10 51260.pdf (accessed 31 July 2011) 